Research Article

\title{
Predictive Modelling and Surface Analysis for Optimization of Production of Biofuel as A Renewable Energy Resource: Proposition of Artificial Neural Network Search
}

\author{
Sri Krishna Murthy, ${ }^{1}$ Ankit Goyal, ${ }^{2}$ N. Rajasekar, ${ }^{3}$ Kapil Pareek, ${ }^{4}$ Thoi Trung Nguyen, ${ }^{5,6}$ \\ and A. Garg $\mathbb{C}^{5,6}$ \\ ${ }^{1}$ Department of Chemical and Biomolecular Engineering, National University of Singapore 117576, Singapore \\ ${ }^{2}$ Institute of Physics, University of Amsterdam, Science Park 904, Amsterdam, Netherlands \\ ${ }^{3}$ Solar Energy Research Cell, School of Electrical Engineering, VIT University, Vellore, India \\ ${ }^{4}$ Centre for Energy \& Environment, Malaviya National Institute of Technology, Jaipur, Rajasthan 302017, India \\ ${ }^{5}$ Division of Computational Mathematics and Engineering, Institute for Computational Science, Ton Duc Thang University, \\ Ho Chi Minh City 700000, Vietnam \\ ${ }^{6}$ Faculty of Civil Engineering, Ton Duc Thang University, Ho Chi Minh City 700000, Vietnam
}

Correspondence should be addressed to A. Garg; akhil1@e.ntu.edu.sg

Received 15 February 2020; Revised 23 April 2020; Accepted 11 June 2020; Published 27 July 2020

Academic Editor: Luis M. López-Ochoa

Copyright (C) 2020 Sri Krishna Murthy et al. This is an open access article distributed under the Creative Commons Attribution License, which permits unrestricted use, distribution, and reproduction in any medium, provided the original work is properly cited.

\begin{abstract}
The present study undertakes the research problem on the optimization of production of biodiesel as a renewable energy resource from the transesterification of soybean oil and ethanol. Predictive modelling and surface analysis techniques were applied based on the artificial neural network search algorithm to correlate the yield of ethyl ester and glycerol and the input parameters. The formulated models accurately predicted the yield of the products with a high coefficient of determination. When the reaction time is low, the ester yield decreases with an increase in temperature and the maximum yield of obtained biodiesel at a very low value of time of reaction and temperature. Plots based on parametric and sensitivity analysis reveals that the yield of ethyl ester can be maximized and that of glycerol minimized at an integrated condition with lower ethanol/oil molar ratio, higher temperature value, higher catalyst concentration value, and longer time of reaction. The global sensitivity analysis reveals that the catalyst concentration and temperature of the reaction influence the yield of ethyl ester the most. In addition, an optimal ethyl ester yield of 95\% can be achieved at specific input conditions. Moreover, according to the results of global sensitivity analysis, the catalyst concentration is found to be most significant for both the glycerol and ethyl ester yield.
\end{abstract}

\section{Introduction}

The environmental impact and the limited availability of the fossil fuels necessitates the use of alternative sources of renewable energy. Biodiesel, a biofuel, is one such alternative source of renewable energy. The demand for biodiesel has seen its production increase tenfold in the past decade [1].
Biodiesel can be manufactured through the transesterification of animal fats or vegetable oils. Transesterification is the general name given for the class of organic reactions, which involve an exchange of alkoxy moiety between an ester and an alcohol. The reaction rate of transesterification can be increased by using a catalyst. The reaction can be acidic, basic, or enzymatic relying on the type 
of catalyst employed. The organic chemical reaction mechanism during the process of transesterification of vegetable oils is shown as follows:

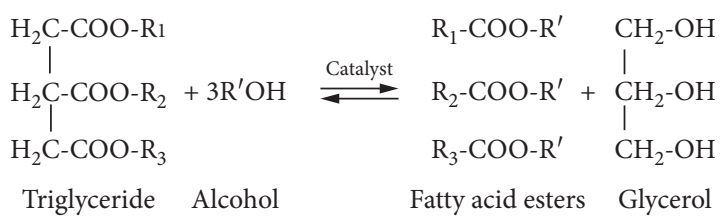

The mechanism of transesterification reaction involves a series of three consecutive and reversible reactions yielding monoglycerides and diglycerides as intermediates [2]:

$$
\begin{aligned}
& \text { 1. Triglyceride }(\mathrm{TG})+\mathrm{R}^{\prime} \mathrm{OH} \stackrel{\text { Catalyst }}{\rightleftarrows} \text { Diglyceride }(\mathrm{DG})+\mathrm{R}^{\prime}-\mathrm{COO}-\mathrm{R}_{1} \\
& \text { 2. Diglyceride }(\mathrm{DG})+\mathrm{R}^{\prime} \mathrm{OH} \stackrel{\text { Catalyst }}{\longleftrightarrow} \text { Monoglyceride }(\mathrm{MG})+\mathrm{R}^{\prime}-\mathrm{COO}-\mathrm{R}_{2}
\end{aligned}
$$

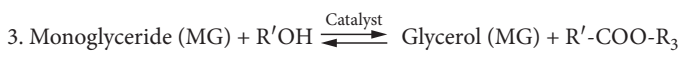

The manufacturing process of biodiesel is presented in Figure 1. To understand the effect of parametric variations and interaction of parameters on the fatty acid ethyl ester (FAEE) yield, it is essential to model the FAEE output as a function of the process variables. Using the model, the process parameters can be optimized to maximize the yield of FAEE.

A number of studies [3-8] have been carried out in the literature to model the FAEE output as a function of process parameters and optimize them to maximize the production of FAEE. Most of these studies [9-15] used response surface methodology (RSM) integrated with central composite design (CCD) of experiments to model the fatty acid ester output as function of some input parameters such as catalyst concentration, alcohol/oil molar ratio, temperature value, agitation rate, and time of reaction, and subsequently optimized them to maximize FAEE output. These studies found that RSM predicted the fatty acid ester output for the data in the given range. The models formulated based on RSM cannot be used for prediction in interpolation or extrapolation cases of data obtained from the processes. RSM holds statistical assumptions such as the validity of accuracy only in the given range of samples and normal distribution of errors and samples. Such assumptions and problems induce uncertainty in accurate predictive modelling and optimization of processes. Avramovic et al. [16] compared the ability of RSM and artificial neural networkgenetic algorithm (ANN-GA) to predict the FAEE output for ethanolysis of sunflower oil and found that the ANN model gave an accurate prediction of FAEE than the RSM model. In this perspective, an artificial intelligence (AI) method such as ANN can be an interesting one to explore, which has the capability to model and optimize the complex multidimensional process based on only the given data $[17,18]$. In the above studies, the studies on production of biodiesel from edible studies is carried out, but it has been produced from nonedible sources as well as evidenced in [19-22].

In the current article, the optimization of biodiesel output from transesterification of soybean oil and ethanol is studied. Soybean oil produces other valuable by-products, such as granules, soybean meal and flour, and glycerin.
Predictive modelling and surface analysis were introduced to explore the ability of the ANN search algorithm to formulate the relationship of yield of ethyl ester and glycerol as an AI model of four input parameters (the temperature, the molar ratio of alcohol/oil, the time of reaction, and the catalyst concentration). The ability of the model to predict the output is quantified in terms of the coefficient of determination $\left(R^{2}\right)$; a high coefficient of determination correlates to an accurate prediction of the output in terms of the inputs. Upon obtaining a reasonably high value of $R^{2}$, the models are further used to carry out sensitivity analysis. Finally, the ethyl ester model is used to optimize the operating conditions to maximize the output of the ethyl ester.

The layout of the article is as follows. Section 1 presents an overview of the transesterification process used to produce biodiesel and the studies carried out in the literature. Section 2 describes and illustrates the research problem undertaken in this study. The predictive modelling methodology based on ANN is illustrated in Section 3. Finally, in Section 4, the results obtained from the sensitivity analysis of the models are discussed. Section 4 also describes the optimization of the operating conditions using the ethyl ester model to maximize the yield of ethyl ester.

\section{Research Problem Undertaken}

The research problem is to optimize the process parameters, viz., temperature, time of reaction, catalyst concentration, and molar ratio of alcohol/oil, to maximize the efficiency of manufacturing of FAEE. To do so, it is essential to model the FAEE output as a function of the process parameters with the least degree of uncertainty. Figure 2 illustrates the research problem undertaken in this study. The ability of the ANN algorithm to predict the ester output using experimental data from the literature is explored. The model is used to conduct sensitivity analysis and study the effect of interaction of process parameters on FAEE output. Sensitivity analysis yields the parameter strongly influencing the output. Furthermore, 2D and 3D surface plots are generated to study the influence of an individual parameter and interaction of parameters, respectively, on the FAEE output. Finally, the model is used to optimize the process parameters to maximize the yield of FAEE. Similarly, to model the response of glycerol as a function of the process parameters, ANN is used. Here also, a sensitivity analysis is conducted to find the parameter strongly affecting the glycerol output and $2 \mathrm{D}$ and $3 \mathrm{D}$ surface plots to study the effect of an individual parameter and interaction of parameters on glycerol output is generated. In short, we aim to do the following in the current study:

(1) Develop a model to accurately predict the FAEE output as a function of the process parameters. The developed model will be used to conduct a sensitivity analysis and study the effect of an individual parameter and interaction of parameters on FAEE output. This model is further used to optimize the process parameters to maximize the yield of FAEE. 


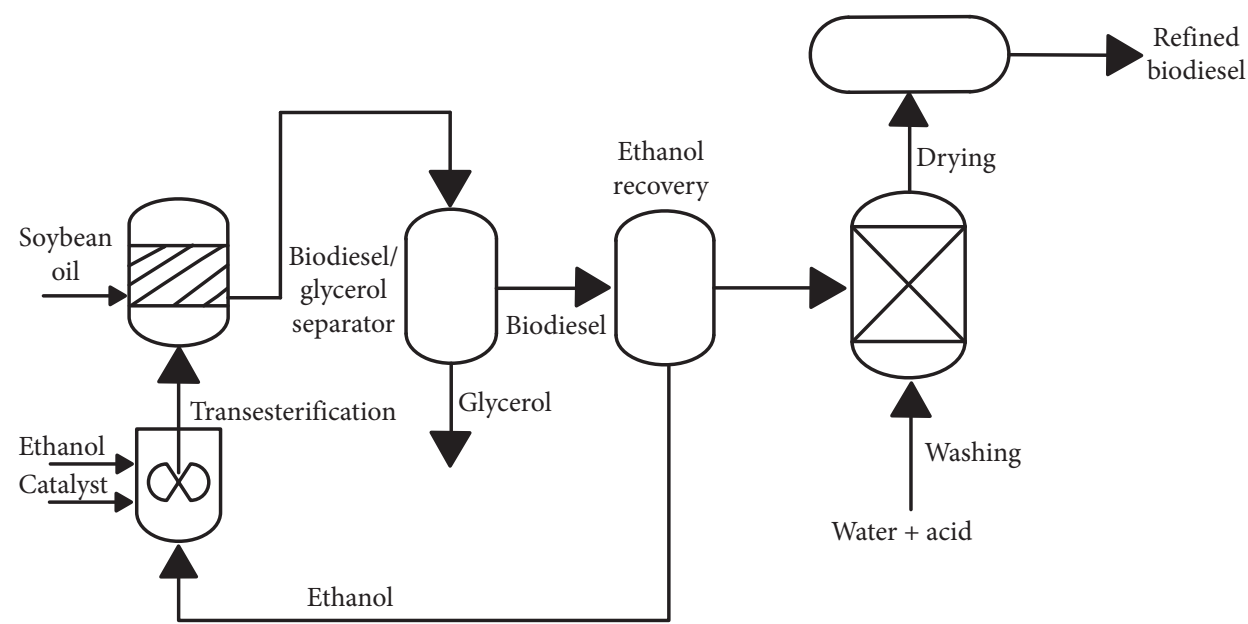

FIGURE 1: The manufacturing process of biodiesel.

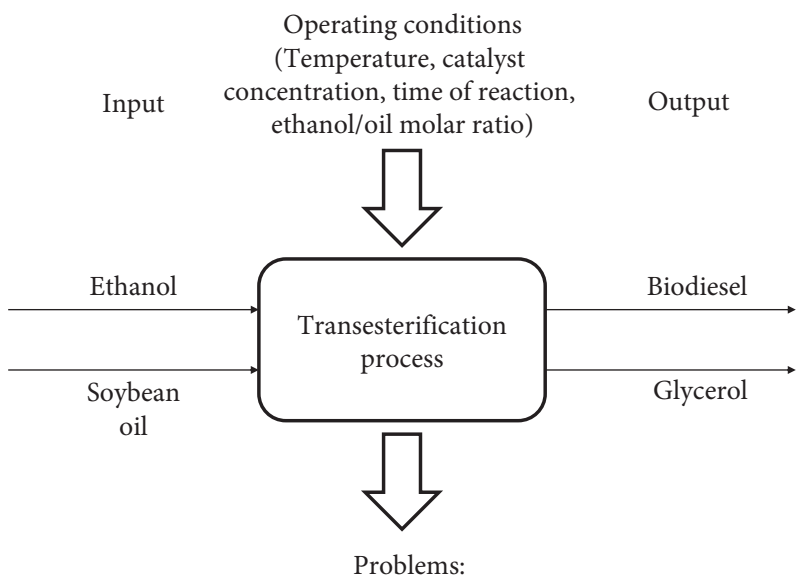

(1) Accurate prediction of biodiesel and glycerol yield

(2) Optimum operating conditions to maximize the yield of biodiesel

FIgURE 2: Illustration of the research problem undertaken in this study.

(2) Similarly, a model will be developed to accurately predict the glycerol output as a function of process parameters and further use this model to conduct a sensitivity analysis and study the effect of an individual parameter and interaction of parameters on the yield of glycerol.

\section{Predictive Modelling Based on ANN}

3.1. Introduction of ANN. ANN is one of the most powerful computation models that simulates the structure and functions of the human brain. ANN is generally applied to formulate nonlinear statistic models to study the complex relationship between various parameters. The basic structure of ANN is shown in Figure 3. Advantages of this modelling tool are the ability to handle parallel information processing, capability of working with incomplete knowledge, and strong fault tolerance. EEY and glycerol yield are affected by a variety of interrelated factors and it is difficult to illustrate their relationships by conventional methods. Therefore, ANN is highly recommended in this regard. In this study, a Multilayer Perceptron Neural Network will be applied to model the data, which is shown in Figure 4.

3.2. Parameter Settings of ANN. Firstly, a set of experimental data is divided into three different sets comprising of training, testing, and validation. The value of seed for sampling is set to 1000. After training, 10 networks are retained for two outputs, respectively. Settings of ANN are shown in Tables 1 and 2 .

\section{Results and Discussion}

4.1. Model for EEY. Figure 5 depicts the distribution of ethyl ester output obtained from the simulation of the model to predict EEY as a function of the operating parameters. 


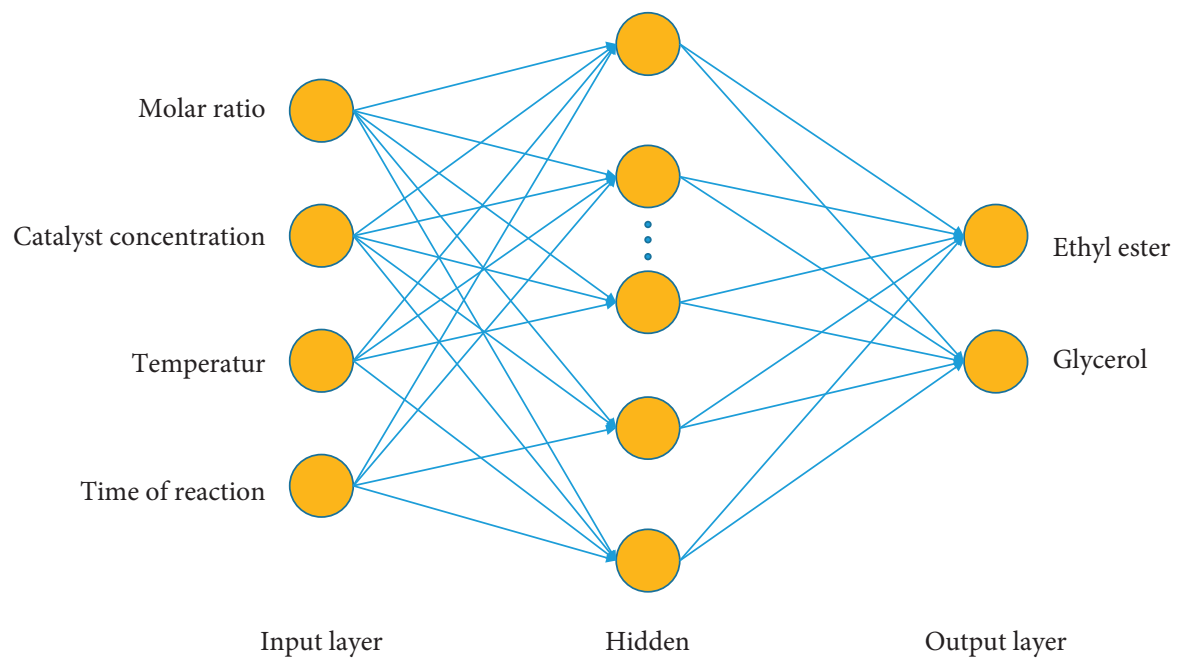

FIGURE 3: The principle of ANN.

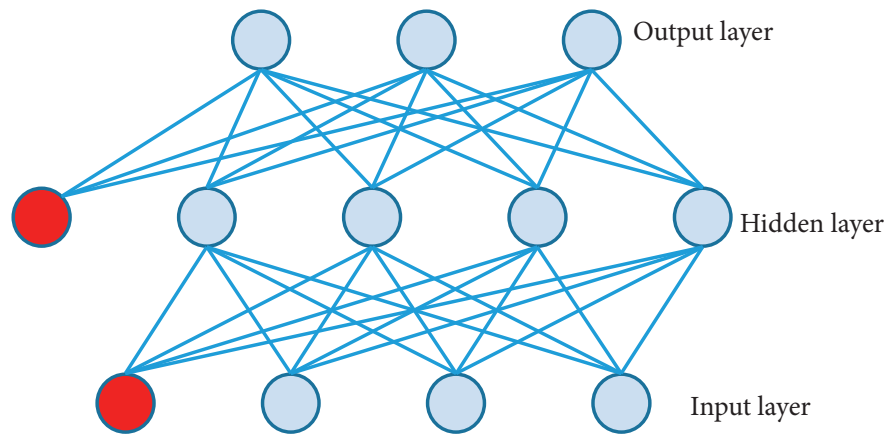

$\bigodot^{\text {Neuron }}$

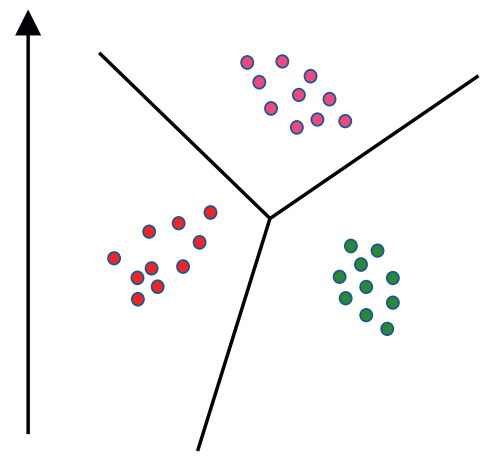

MLP

FIgURE 4: The multilayer perceptron neural networks.

TABle 1: Settings of ANN for output ethyl ester.
Modelling parameter settings

Percentage of training dataset

Percentage of test dataset

Percentage of validation dataset

Number of networks to train

Number of hidden layers
Number of networks to retain
Detail value

$80 \%$

$10 \%$

$10 \%$

300

10

10
TABLE 2: Settings of ANN for output glycerol.

\begin{tabular}{lc}
\hline Modelling parameter settings & Detail value \\
\hline Percentage of training dataset & $75 \%$ \\
Percentage of test dataset & $15 \%$ \\
Percentage of validation dataset & $10 \%$ \\
Number of networks to train & 500 \\
Number of networks to retain & 10 \\
Number of hidden layers & 9 \\
\hline
\end{tabular}

Figure 5 concludes EEY between $-10 \%$ and $150 \%$ with the yield following an approximate normal trend.

Furthermore, to understand how variation in the operating conditions affects ethyl ester, the $2 \mathrm{D}$ plots are generated according to the obtained ANN model. Figure 6(b) shows that the EEY follows a sinusoidal curve as the catalyst concentration and ultimately attains a constant value of $93 \%$ at 1.2 wt. \% catalyst concentration. Figure 6(a) depicts the monotonic increase in EEY with increase in the ethanol/oil molar ratio. Figure 6(c) shows that the EEY approximately follows a cubic curve as the time of reaction is increased. The EEY follows a sinusoidal curve as the temperature is increased, as shown in Figure 6(d).

Subsequently, 3D surface plots are generated to study the influence of interaction of input parameters on EEY. From Figures 7(a)-7(c), it is clearly visible that the maximum EEY is obtained for ethanol/oil molar ratios in the range of 10-12 for higher temperature value, higher catalyst concentration value, and longer reaction time, which is in accordance with the findings of Fillieres et al. [23]. Figure 7(e) clearly shows 
Profiles for predicted values
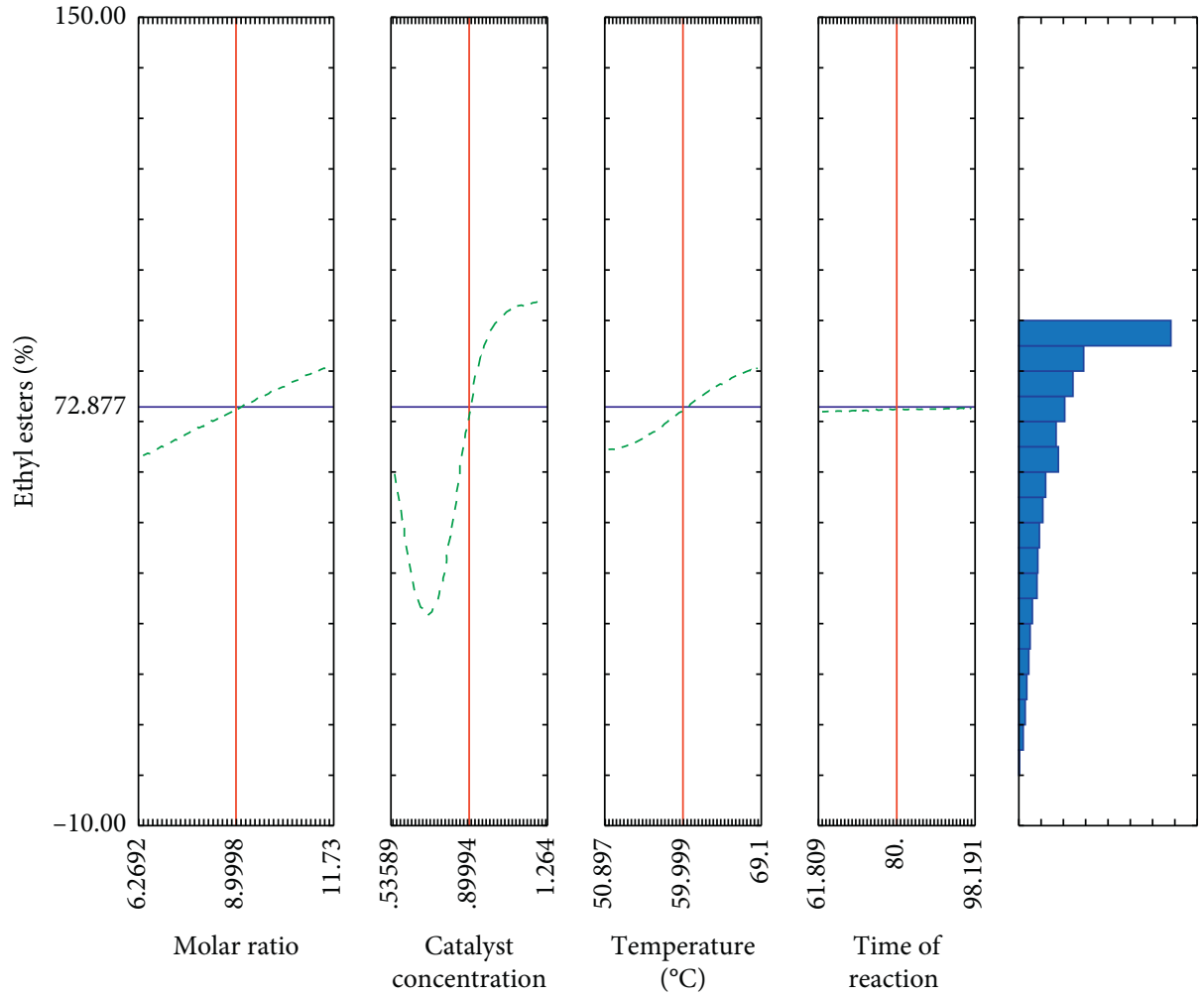

FIgURE 5: Ethyl ester distribution from the simulation of the model.

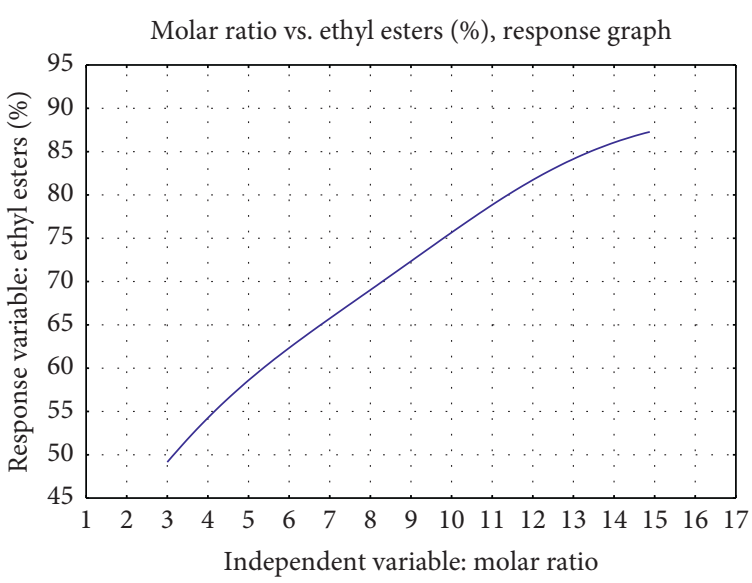

(a)

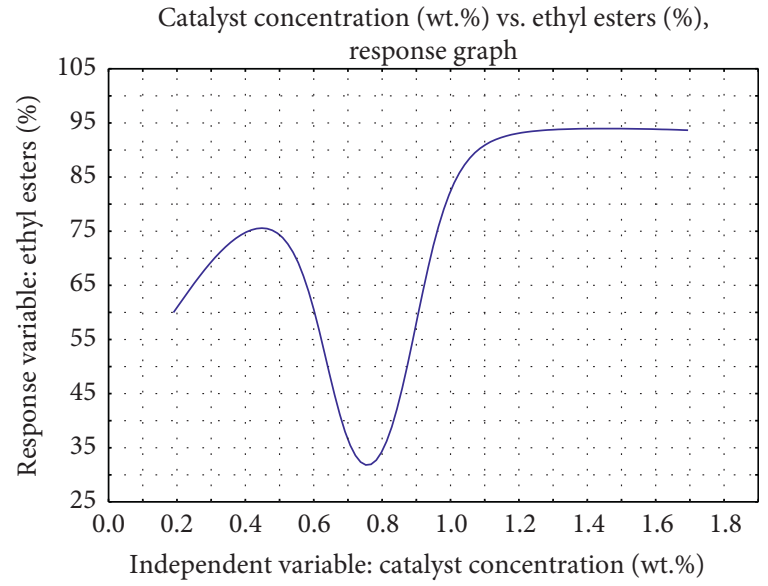

(b)

Figure 6: Continued. 
Time of reaction ( $\mathrm{min})$ vs. ethyl esters (\%), response graph

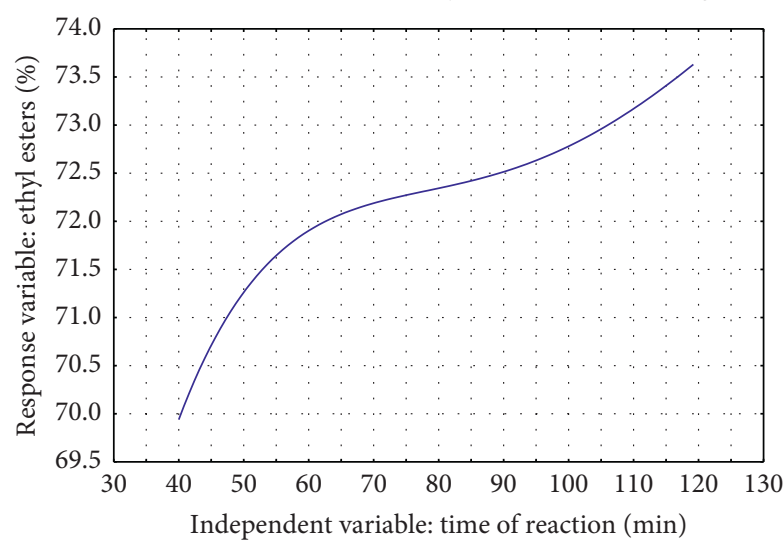

(c)
Temperature $\left({ }^{\circ} \mathrm{C}\right)$ vs. ethyl esters $(\%)$, response graph

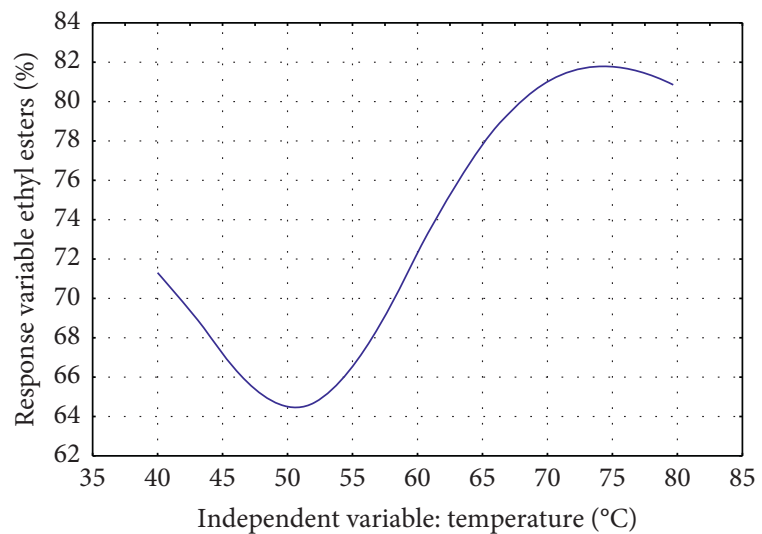

(d)

Figure 6: The dynamic relationship between ethyl ester output and inputs.

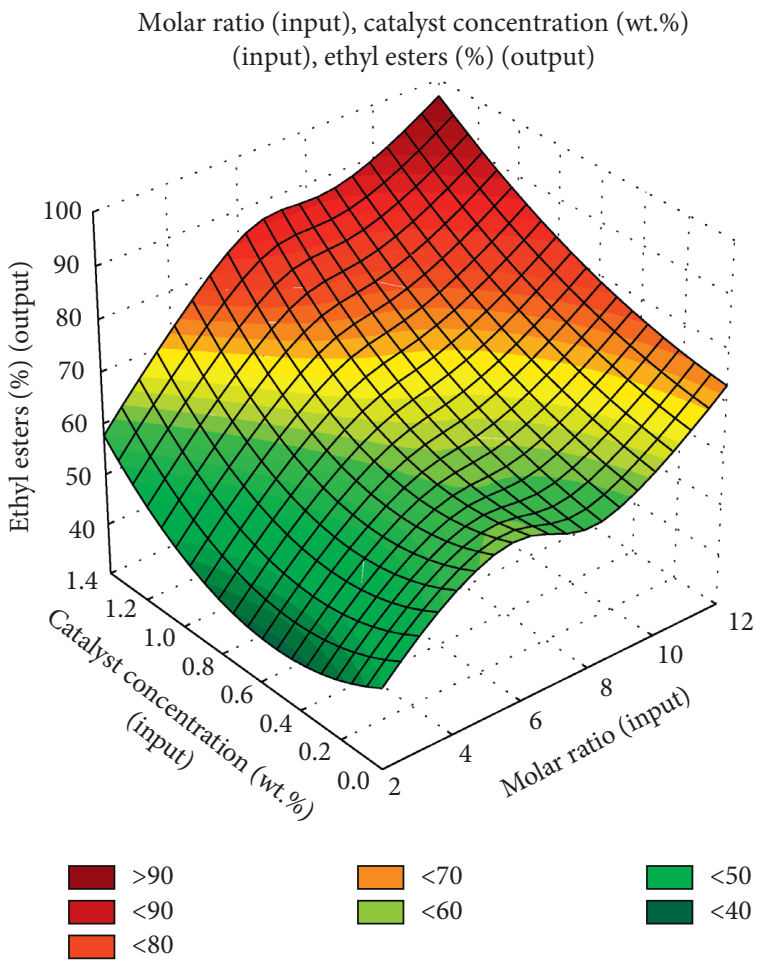

(a)

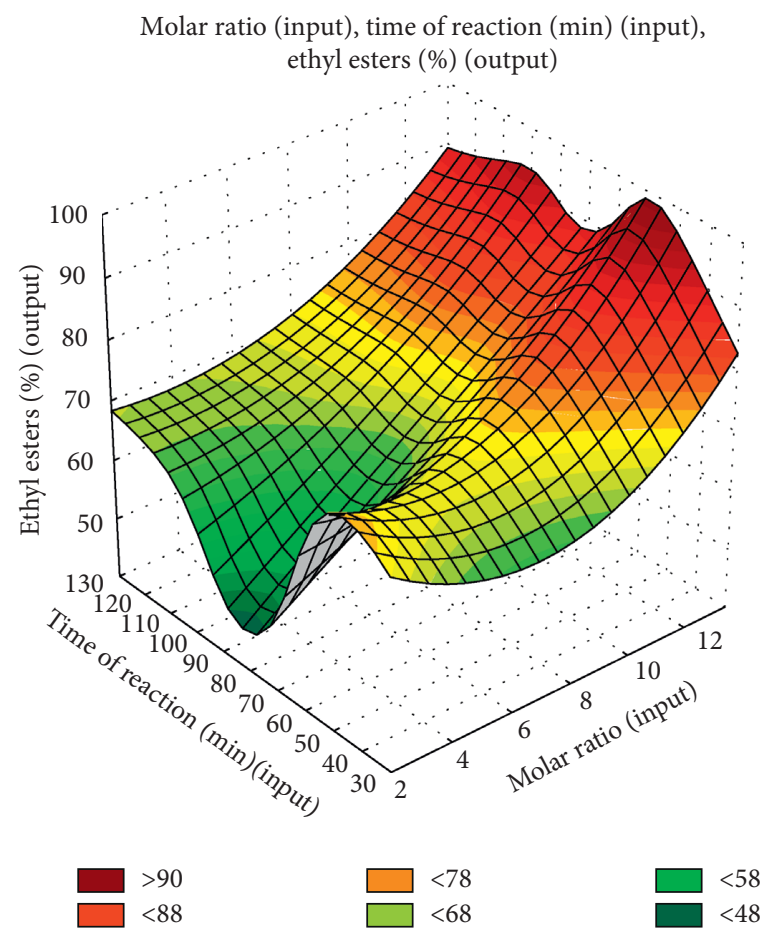

(b)

Figure 7: Continued. 

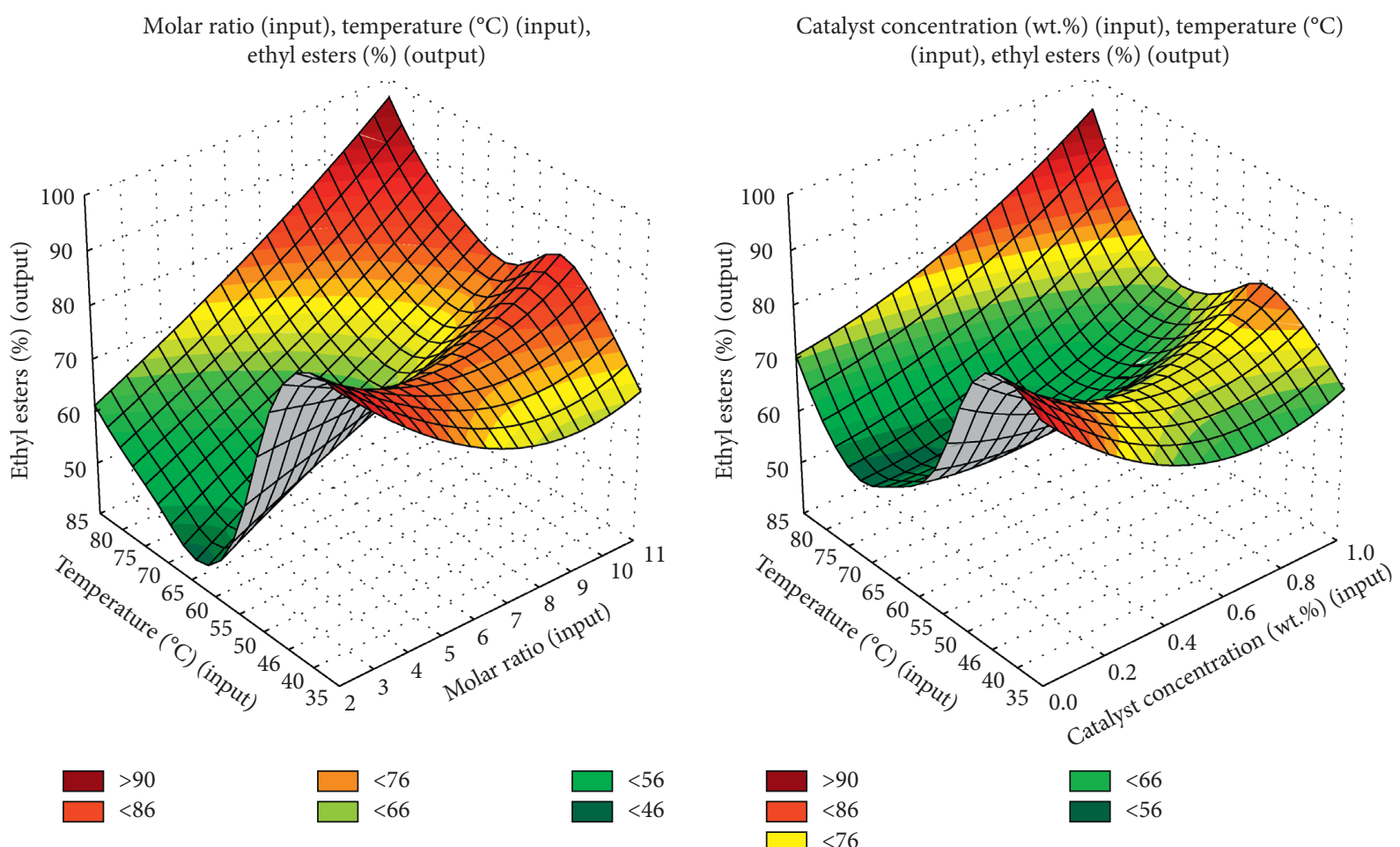

(c)

(d)

Catalyst concentration (wt.\%) (input), time of reaction (min) (input), ethyl esters (\%) (output)

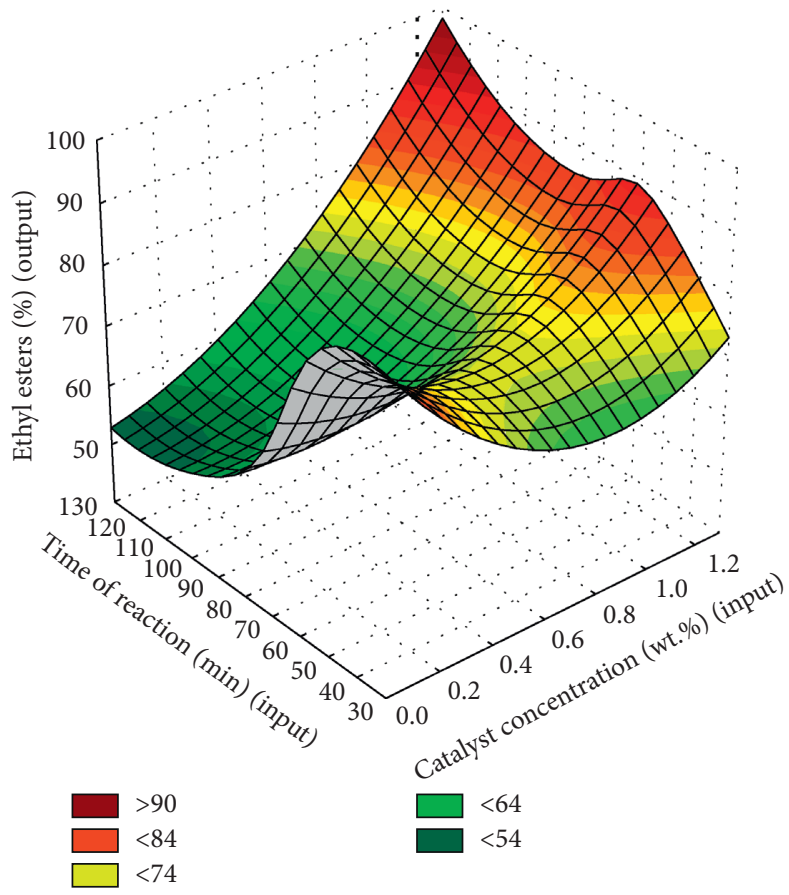

(e)

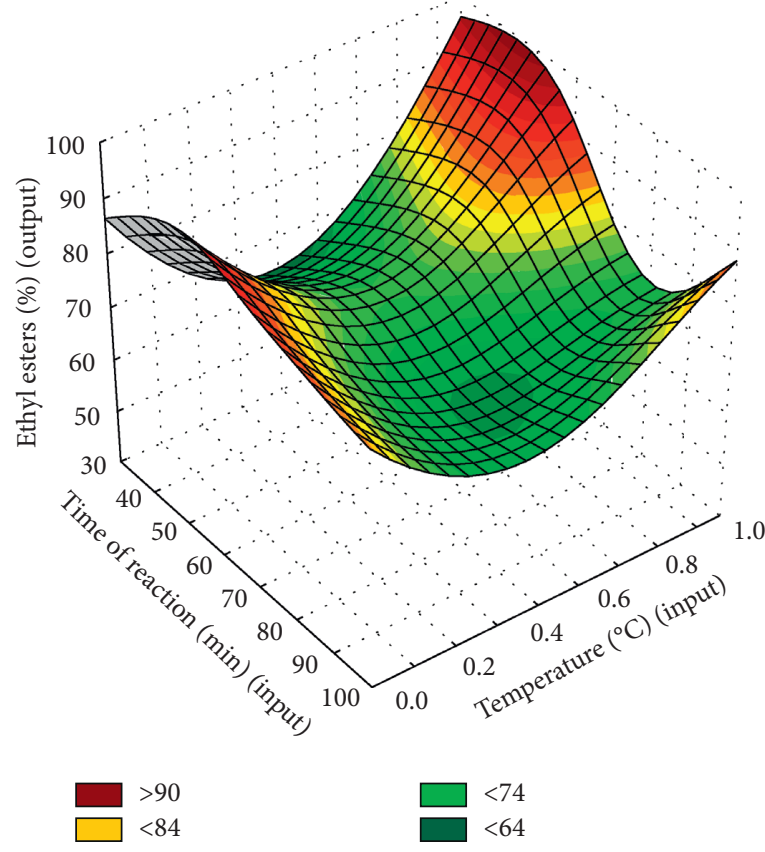

(f)

Figure 7: 3D dynamic relationships between every two inputs' parameters and ethyl ester output. 


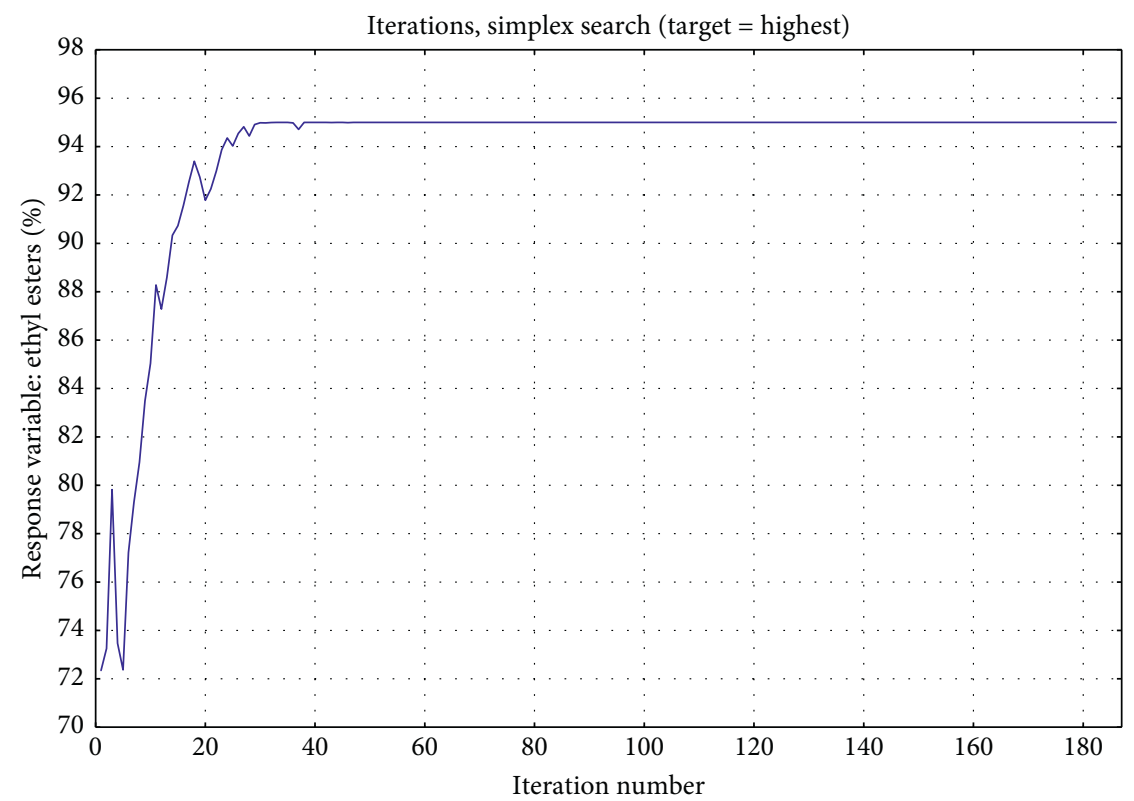

Figure 8: Optimization results for EEY based on the obtained ANN model.

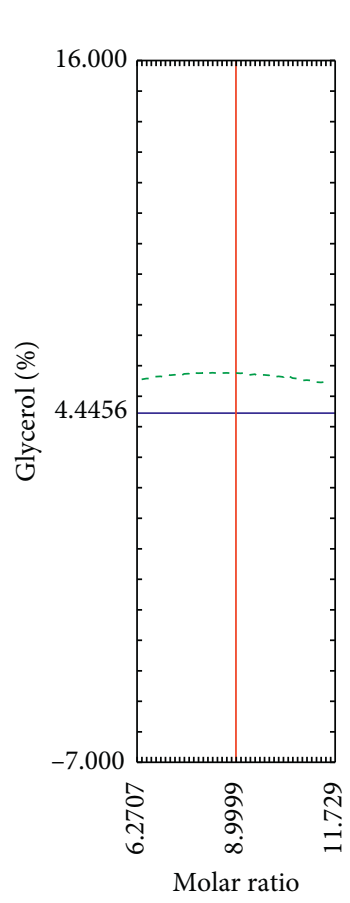

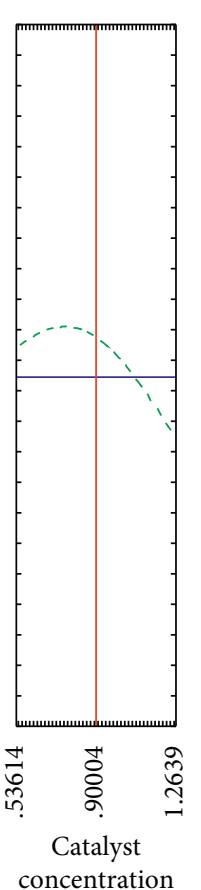

(wt.\%)

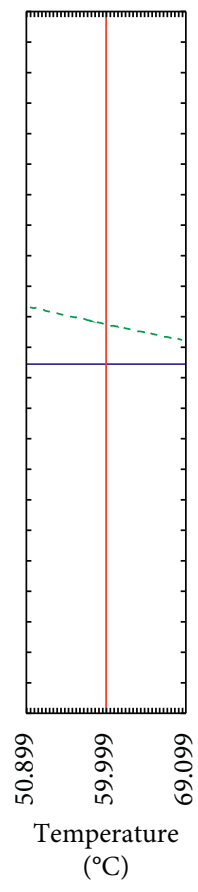

$\left({ }^{\circ} \mathrm{C}\right)$

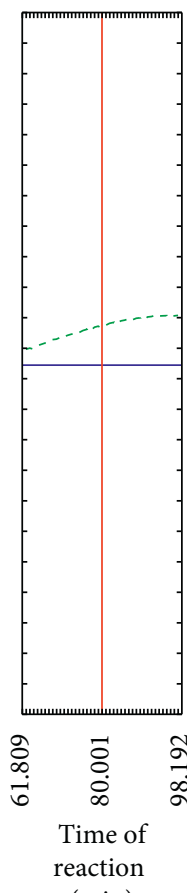

(min)

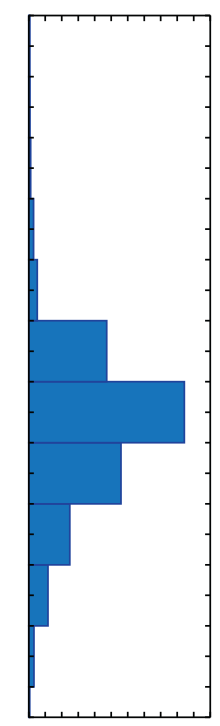

FIgURE 9: Glycerol yield distribution from the simulation of the model.

that, for a given value of temperature, the output increases with increase in catalyst concentration. Figure $7(\mathrm{~d})$ shows that, for the time of reaction $<90 \mathrm{~min}$, the output decreases with increasing catalyst concentration, whereas the opposite happens when the time of reaction reaches $>90 \mathrm{~min}$. The opposite happens for low reaction times $(<40 \mathrm{~min})$, i.e., the output decreases with increase in temperature and the maximum yield of ethyl ester is obtained at a very low value of time of reaction and temperature. For a given time of reaction, the output increases with increase in temperature, as shown in Figure 7(f). At low catalyst concentration, an increase in temperature leads to an increase in EEY. Moreover, at any given catalyst concentration, the EEY increases with a linear increase in temperature. The above observations are in accordance with those made in [6-18]. Finally, the optimization of the model is carried out using a 


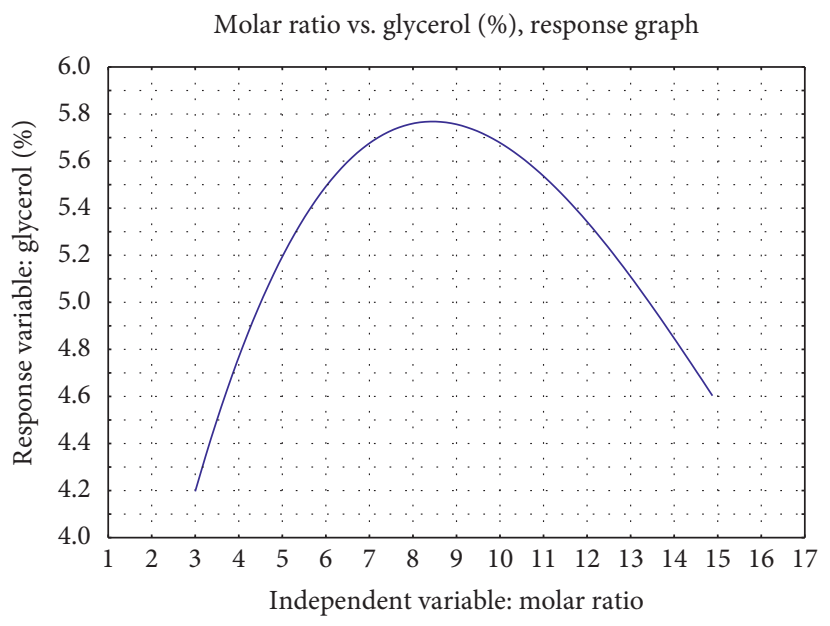

(a)

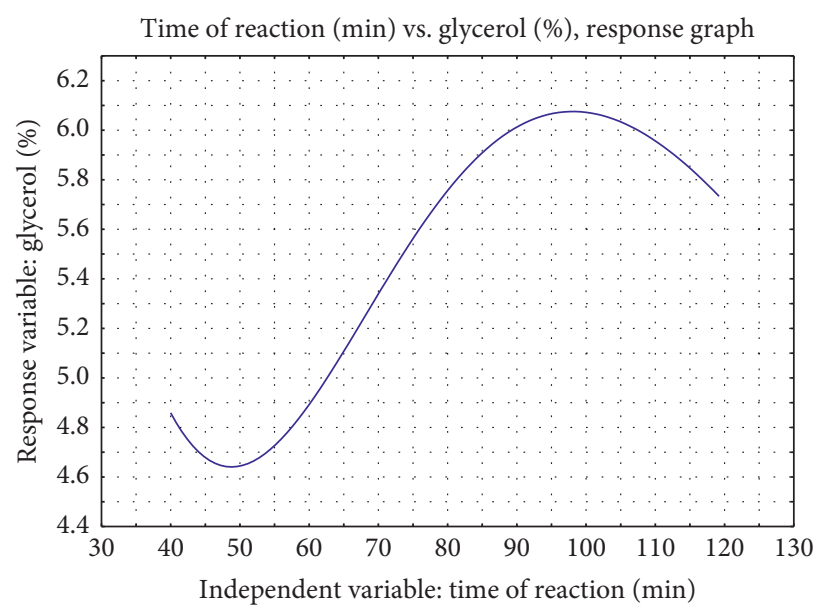

(c)

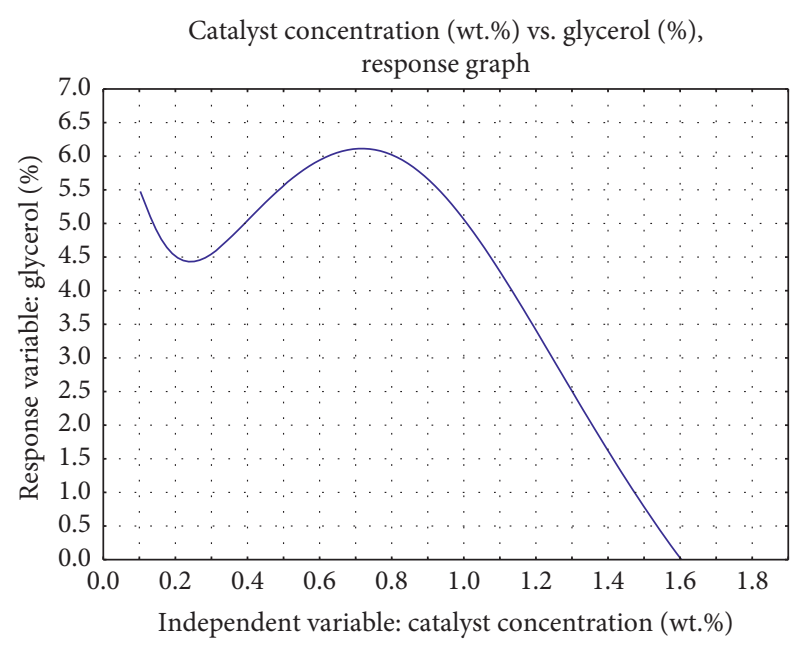

(b)

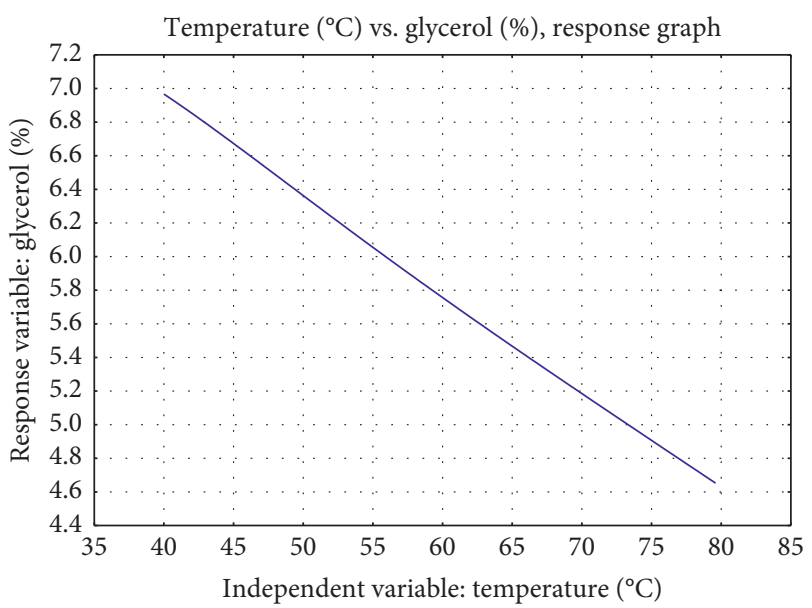

(d)

FIGURE 10: The dynamic relationship between glycerol yield output and inputs.

simplex approach to maximize the yield of ethyl ester. The pareto front (Figure 8) reveals that a maximum EEY of $95 \%$ was obtained when the value of temperature is $39.6^{\circ} \mathrm{C}$, the value of catalyst concentration is $1.35 \mathrm{wt} \%$, the time of reaction is $81 \mathrm{~min}$, and the ratio of alcohol/oil molar is $10: 1$.

4.2. Model for Glycerol Yield. As in the case of ethyl ester, Figure 9 shows a distribution of the glycerol yield between $-7 \%$ to $16 \%$. 2D plots are shown to observe the effect of variation in operating condition on the glycerol yield. From Figure 10(a), we can clearly see that the output follows an inverted parabolic profile with increase in the molar ratio. The output follows a sinusoidal curve first and then declines linearly with the value of catalyst concentration increase, as shown in Figure 10(b). Figure 10(c) depicts the sinusoidal curve of the output with increase in time of reaction. And the output monotonically decreases with increase in temperature, as shown in Figure 10(d).

Furthermore, the 3D surface plots are generated to investigate the influence of interaction of experimental input parameters on the output. According to Figures 11(a), 11(d), and 11(e), maximum glycerol yield is obtained with high ethanol/oil molar ratios and low time of reaction, catalyst concentration, and temperature. Figures 11(b) and 11(c) show that the glycerol yield is maximum for low catalyst concentration at a short time of reaction and at a low temperature. Figure 11(f) depicts the increase in glycerol yield with increase in temperature at high time of reaction. Combining the results presented in Figure 11, EEY is maximum and that of glycerol is minimum for the lower molar ratio of ethanol/oil and longer reaction time and high catalyst concentration value, as well as high temperature value.

4.3. Sensitivity Analysis of Formulated Models. Global sensitivity analysis was performed to see the relative significance of the parameters for the yield of ethyl and glycerol based on the optimal ANN model. From Figure 12, the catalyst concentration (64\%) is the most significant factor for glycerol yield. Temperature (21\%) has relatively higher impact on ethyl esters, and third is the molar ratio (17\%). Time of reaction has less contribution compared to the other 
Molar ratio (input), time of reaction (min) (input), glycerol (\%) (output)
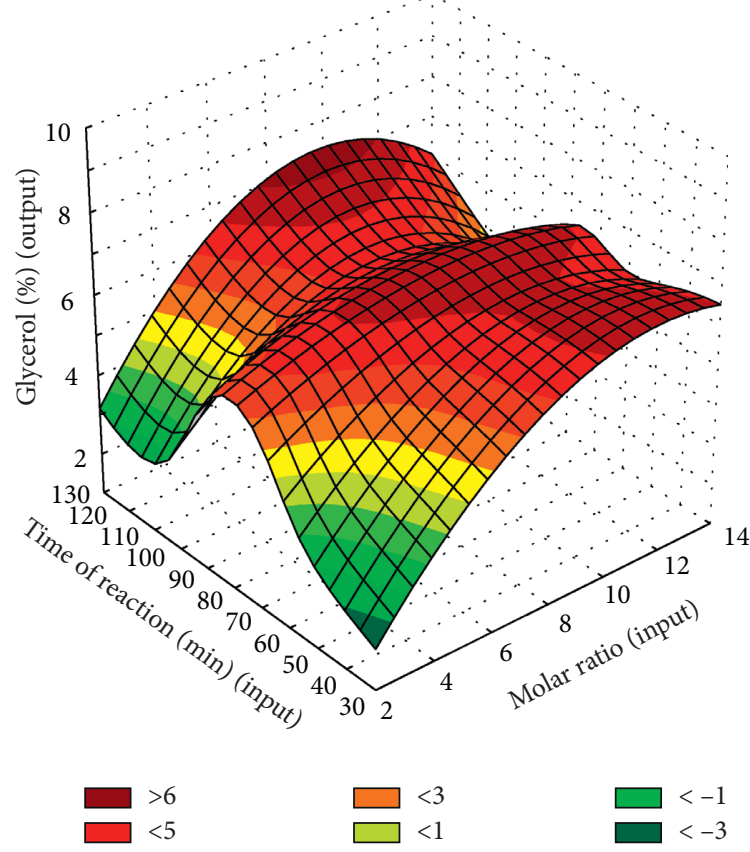

(a)

Catalyst concentration (wt.\%) (input), temperature $\left({ }^{\circ} \mathrm{C}\right)$ (input), glycerol (\%) (output)

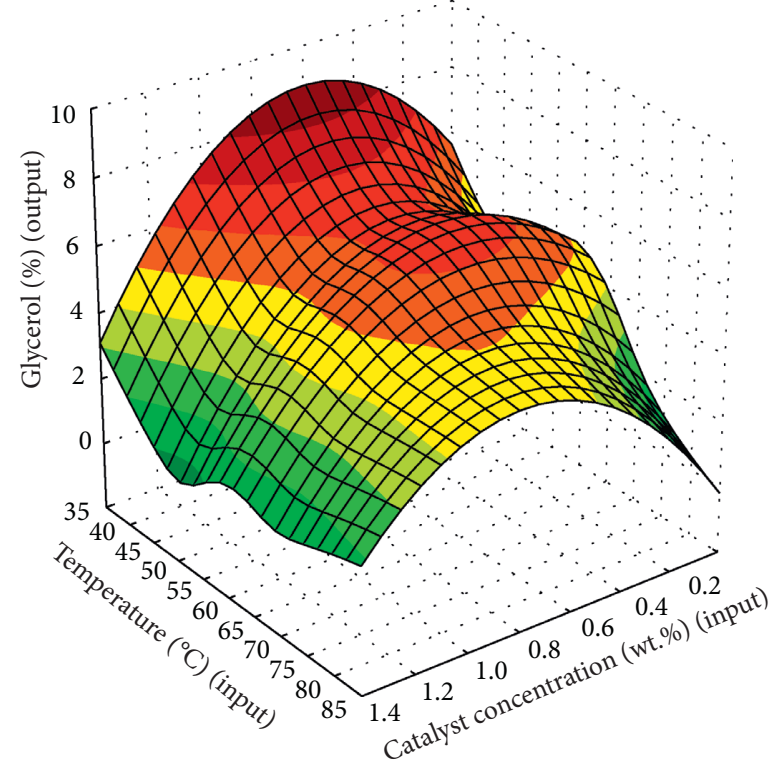

Catalyst concentration (wt.\%) (input), time of reaction (min) (input), glycerol (\%) (output)

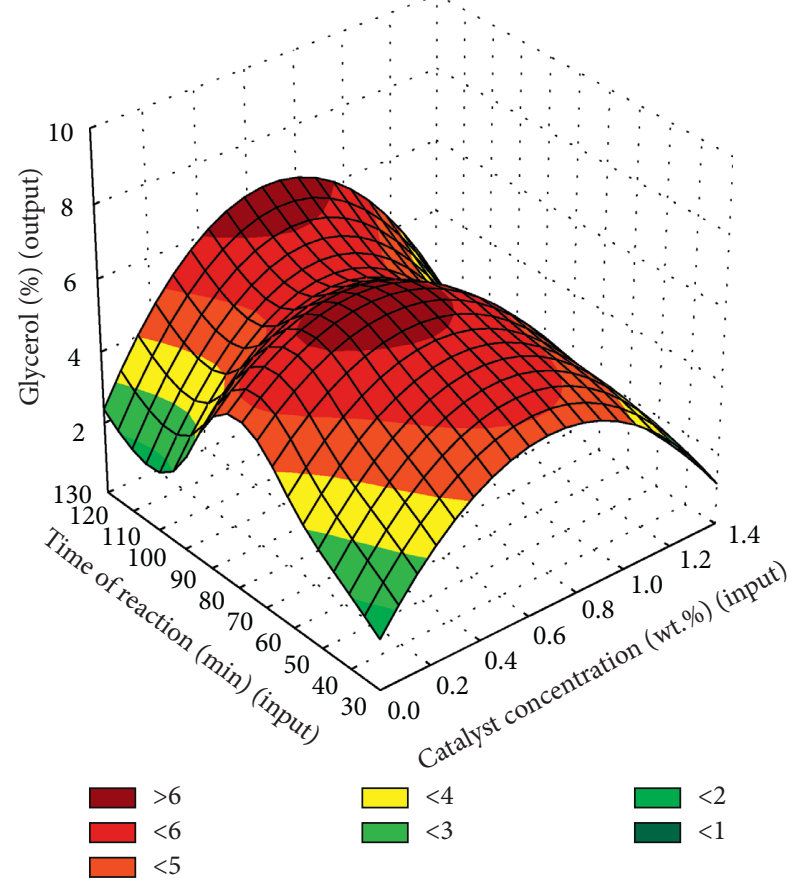

(b)

Molar ratio (input), temperature $\left({ }^{\circ} \mathrm{C}\right)$ (input), glycerol (\%) (output)
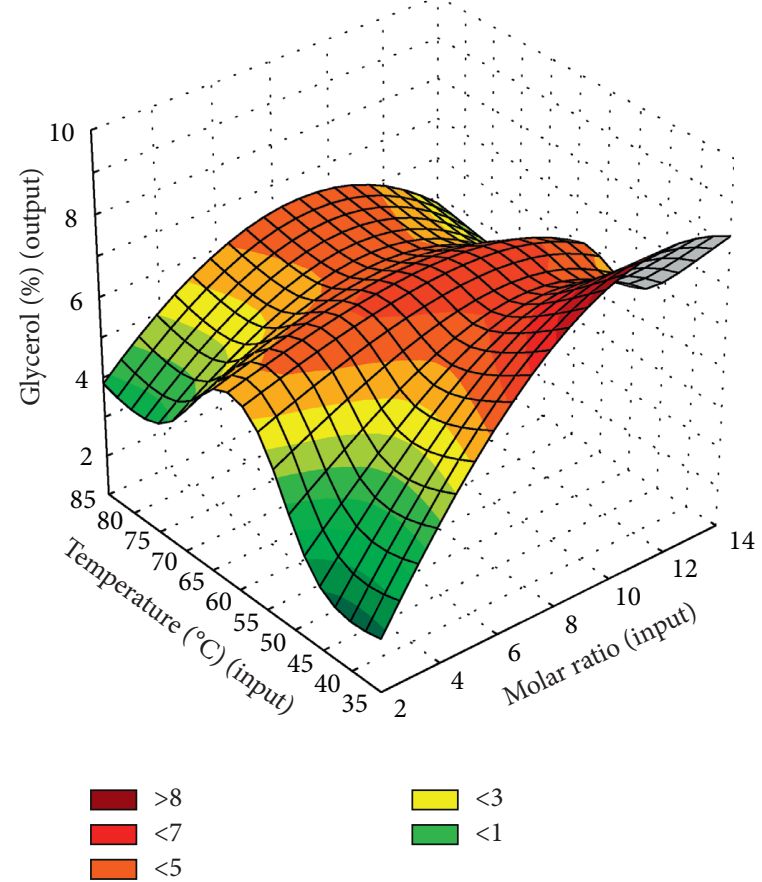

(d)

Figure 11: Continued. 


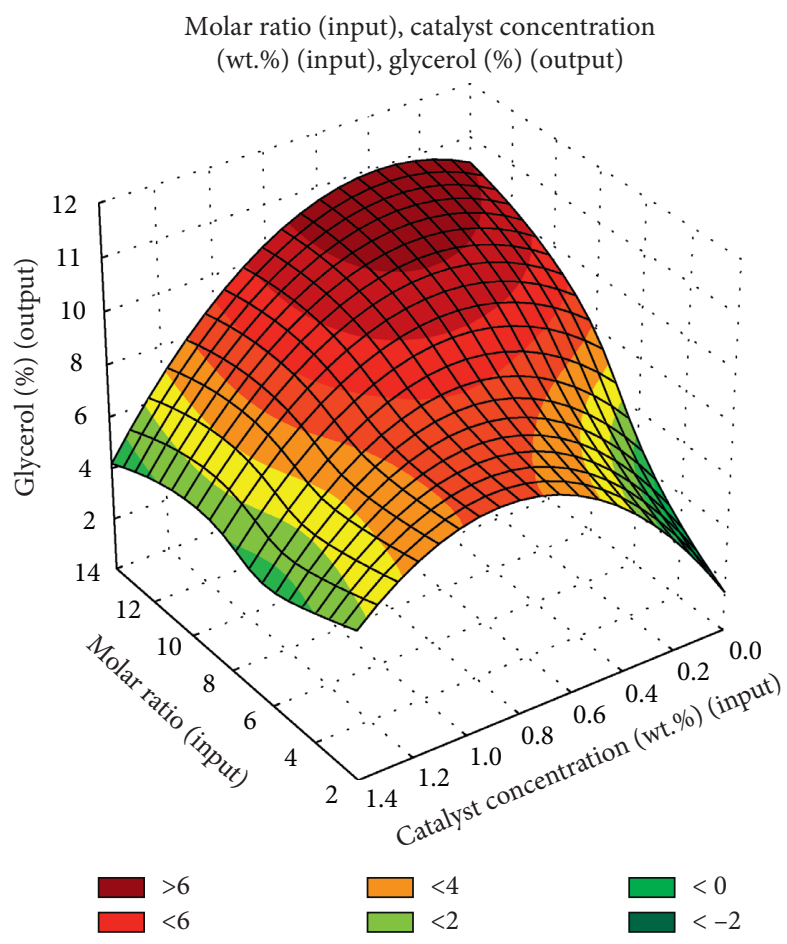

(e)

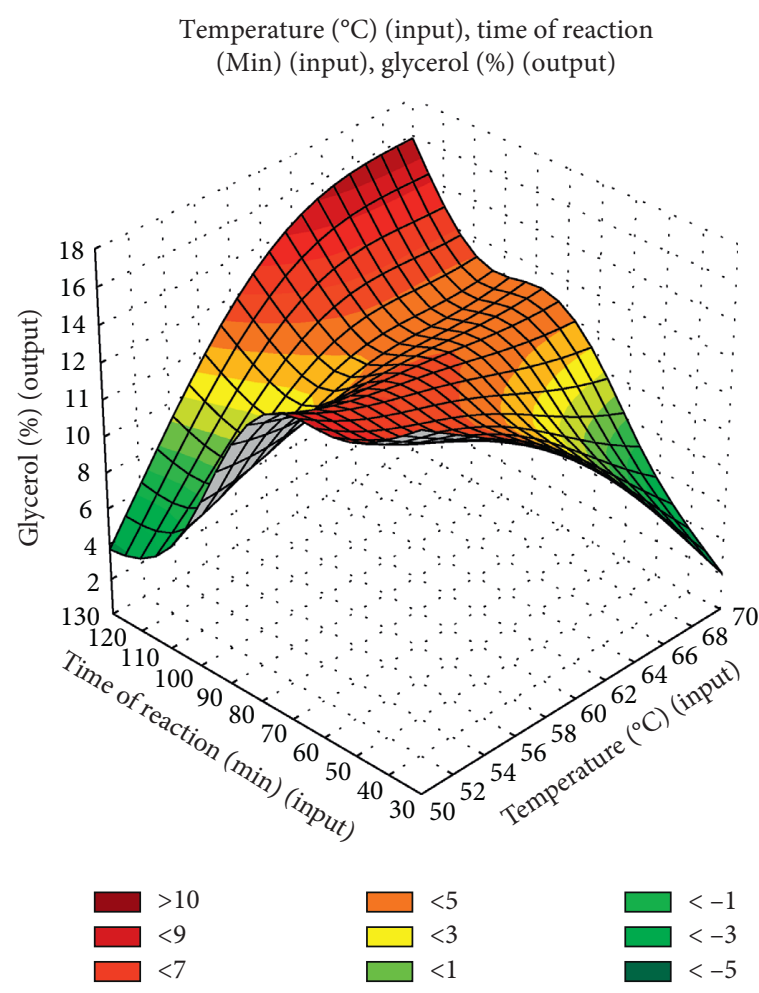

(f)

FIGURE 11: 3D dynamic relationships between every two inputs' parameters and glycerol yield output.
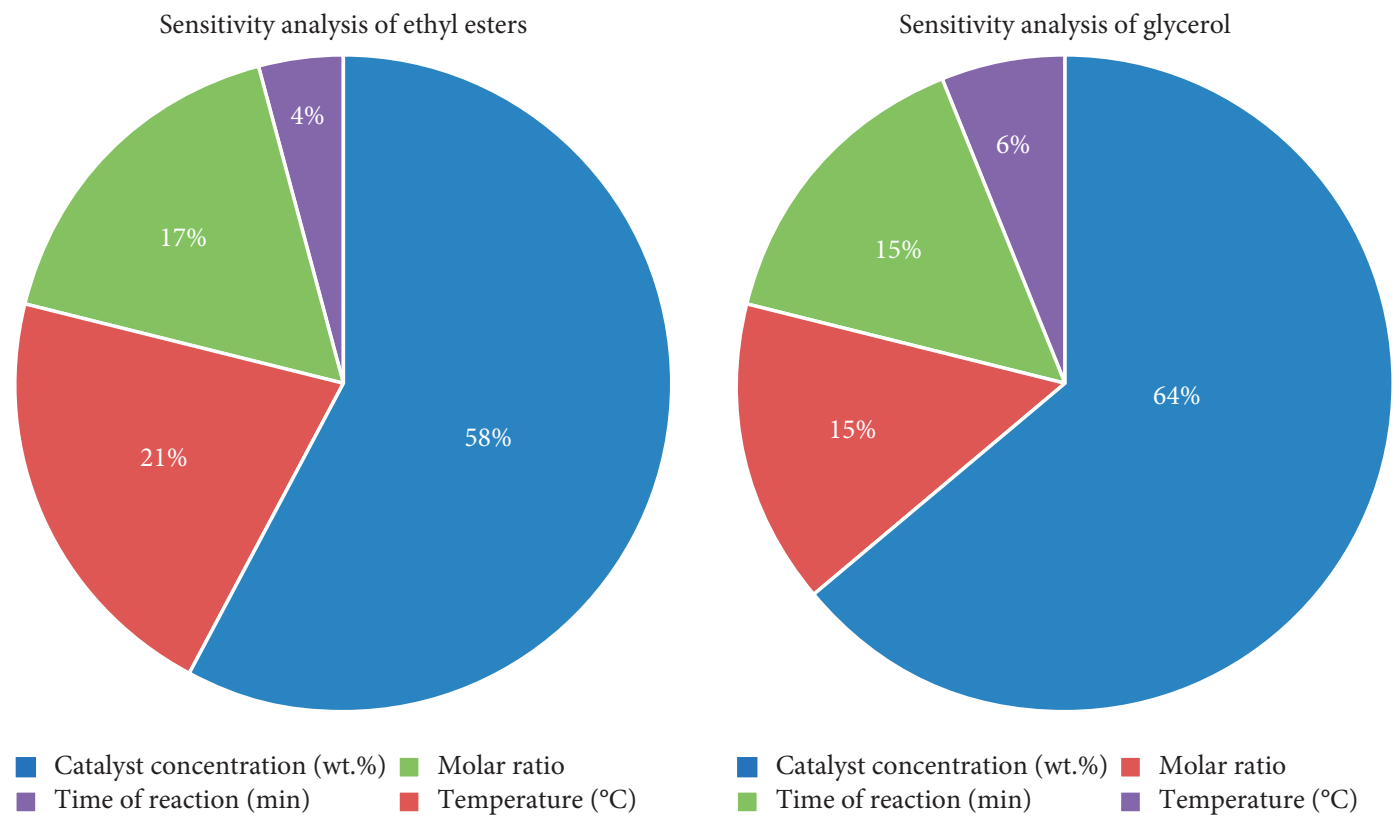

FIGURE 12: Sensitivity analysis of ethyl ester and glycerol showing contribution of input operating conditions on the ethyl esters and glycerol yields.

parameters. The contributions to glycerol are quite different except for catalyst concentration (64\%), which also has most crucial contribution to ethyl esters. The molar ratio and the time of reaction contributes $15 \%$ and $15 \%$, respectively. The least important factor is temperature, contributing $6 \%$ to glycerol. 


\section{Conclusions}

In this study, an ANN search algorithm coupled with surface response optimization techniques was used to investigate the optimal production condition as well as the efficiency of produced biodiesel. The main conclusions are as follows:

(1) The formulated models accurately predicted the yield of the products with a high coefficient of determination $\left(R^{2}=0.99\right)$

(2) When the value of ethanol/oil was between 10 and 12, the maximum efficiency of ethyl ester can be obtained

(3) Among the input operation conditions, catalyst concentration (64\%) is found to be the most significant for both the glycerol and EEYs

(4) The yield of ethyl ester can be maximized and that of glycerol can be minimized at the lower molar ratio of ethanol/oil, higher temperature, longer time of reaction, and higher catalyst concentration

(5) A maximum EEY of $95 \%$ was obtained when the value of temperature is $39.6^{\circ} \mathrm{C}$, the value of catalyst concentration is $1.35 \mathrm{wt} . \%$, the time of reaction is $81 \mathrm{~min}$, and the ratio of alcohol/oil molar is $10: 1$

The current study can be extended to study the influence of additional parameters such as agitation speed of the stirrer, type of catalyst used, the type of alcohol used, and the type of vegetable oil used.

\section{Data Availability}

The numerical data used to support the findings of this study are included within the article.

\section{Disclosure}

The author, A. Garg, is currently in School of Chemical, Biological and Environmental Engineering, Oregon State University, Corvallis, 97331, USA.

\section{Conflicts of Interest}

The authors declare that they have no conflicts of interest.

\section{Acknowledgments}

The authors would like to acknowledge Grant DMETKF2018019 by State Key Lab of Digital Manufacturing Equipment \& Technology (Huazhong University of Science and Technology).

\section{References}

[1] REN21, Renewables 2014 Global Status Report, REN21 Secretariat, Paris, France, 2014.

[2] B. Freedman, R. O. Butterfield, and E. H. Pryde, "Transesterification kinetics of soybean oil 1," Journal of the American Oil Chemists' Society, vol. 63, no. 10, pp. 1375-1380, 1986.
[3] D. Zeng, L. Yang, and T. Fang, "Process optimization, kinetic and thermodynamic studies on biodiesel production by supercritical methanol transesterification with $\mathrm{CH}_{3} \mathrm{ONa}$ catalyst," Fuel, vol. 203, pp. 739-748, 2017.

[4] N. García-Martínez, P. Andreo-Martínez, J. Quesada-Medina et al., "Optimization of non-catalytic transesterification of tobacco (Nicotiana tabacum) seed oil using supercritical methanol to biodiesel production," Energy Conversion and Management, vol. 131, pp. 99-108, 2017.

[5] C. Muthukumaran, R. Praniesh, P. Navamani, R. Swathi, G. Sharmila, and N. Manoj Kumar, "Process optimization and kinetic modeling of biodiesel production using non-edible Madhuca indica oil," Fuel, vol. 195, pp. 217-225, 2017.

[6] M. Karimi, B. Jenkins, and P. Stroeve, "Multi-objective optimization of transesterification in biodiesel production catalyzed by immobilized lipase," Biofuels, Bioproducts and Biorefining, vol. 10, no. 6, pp. 804-818, 2016.

[7] F. H. Alhassan, U. Rashid, and Y. H. Taufiq-Yap, "Optimization of simultaneous production of waste cooking oil basedbiodiesel using iron-manganese doped zirconia-supported molybdenum oxide nanoparticles catalyst," Journal of Renewable and Sustainable Energy, vol. 8, no. 3, Article ID 033101, 2016.

[8] G. T. Ang, S. N. Ooi, K. T. Tan, K. T. Lee, and A. R. Mohamed, "Optimization and kinetic studies of sea mango (Cerbera odollam) oil for biodiesel production via supercritical reaction," Energy Conversion and Management, vol. 99, pp. 242251, 2015.

[9] M. Sánchez, F. Bergamin, E. Peña, M. Martínez, and J. Aracil, "A comparative study of the production of esters from Jatropha oil using different short-chain alcohols: optimization and characterization," Fuel, vol. 143, pp. 183-188, 2015.

[10] J. K. Poppe, C. R. Matte, M. d. C. R. Peralba, R. FernandezLafuente, R. C. Rodrigues, and M. A. Z. Ayub, "Optimization of ethyl ester production from olive and palm oils using mixtures of immobilized lipases," Applied Catalysis A: General, vol. 490, pp. 50-56, 2015.

[11] H. V. Lee, R. Yunus, J. C. Juan, and Y. H. Taufiq-Yap, "Process optimization design for jatropha-based biodiesel production using response surface methodology," Fuel Processing Technology, vol. 92, no. 12, pp. 2420-2428, 2011.

[12] K. F. Yee, J. Kansedo, and K. T. Lee, "Biodiesel production from palm oil via heterogeneous transesterification: optimization study," Chemical Engineering Communications, vol. 197, no. 12, pp. 1597-1611, 2010.

[13] A. Z. Abdullah, N. Razali, and K. T. Lee, "Optimization of mesoporous K/SBA-15 catalyzed transesterification of palm oil using response surface methodology," Fuel Processing Technology, vol. 90, no. 7-8, pp. 958-964, 2009.

[14] B. O. Ighose, I. A. Adeleke, M. Damos, H. A. Junaid, K. E. Okpalaeke, and E. Betiku, "Optimization of biodiesel production from Thevetia peruviana seed oil by adaptive neuro-fuzzy inference system coupled with genetic algorithm and response surface methodology," Energy Conversion and Management, vol. 132, pp. 231-240, 2017.

[15] A. Sarve, S. S. Sonawane, and M. N. Varma, "Ultrasound assisted biodiesel production from sesame (Sesamum indicum L.) oil using barium hydroxide as a heterogeneous catalyst: comparative assessment of prediction abilities between response surface methodology (RSM) and artificial neural network (ANN)," Ultrasonics Sonochemistry, vol. 26, pp. 218-228, 2015.

[16] J. M. Avramovic, A. V. Velickovic, O. S. Stamenkovic, K. M. Rajkovic, P. S. Milic, and V. B. Veljkovic, "Optimization 
of sunflower oil ethanolysis catalyzed by calcium oxide: RSM versus ANN-GA," Energy Conversion and Management, vol. 105, pp. 1149-1156, 2015.

[17] E. Betiku and S. O. Ajala, "Modeling and optimization of Thevetia peruviana (yellow oleander) oil biodiesel synthesis via Musa paradisiacal (plantain) peels as heterogeneous base catalyst: a case of artificial neural network vs. response surface methodology," Industrial Crops and Products, vol. 53, pp. 314-322, 2014.

[18] M. Rajendra, P. C. Jena, and H. Raheman, "Prediction of optimized pretreatment process parameters for biodiesel production using ANN and GA," Fuel, vol. 88, no. 5, pp. $868-875,2009$.

[19] A. K. Ayoob and A. B. Fadhil, "Valorization of waste tires in the synthesis of an effective carbon based catalyst for biodiesel production from a mixture of non-edible oils," Fuel, vol. 264, pp. 116754-116766, 2020.

[20] N. Damanik, H. C. Ong, W. T. Chong, and A. S. Silitonga, "Biodiesel production from Calophyllum inophyllum-palm mixed oil," Energy Sources, Part A: Recovery, Utilization, and Environmental Effects, vol. 39, no. 12, pp. 1283-1289, 2017.

[21] A. B. Fadhil, A. W. Nayyef, and S. H. Sedeeq, "Valorization of mixed radish seed oil and Prunus armeniaca L. oil as a promising feedstock for biodiesel production: evaluation and analysis of biodiesels," Asia-Pacific Journal of Chemical Engineering, vol. 15, no. 1, pp. 2390-2404, 2019.

[22] A. K. Ayoob and A. B. Fadhil, "Biodiesel production through transesterification of a mixture of non-edible oils over lithium supported on activated carbon derived from scrap tires," Energy Conversion and Management, vol. 201, pp. 112149112161, 2019.

[23] R. Fillières, B. Benjelloun-Mlayah, and M. Delmas, "Ethanolysis of rapeseed oil: quantitation of ethyl esters, mono-, di-, and triglycerides and glycerol by high-performance size-exclusion chromatography," Journal of the American Oil Chemists' Society, vol. 72, no. 4, pp. 427-432, 1995. 